\title{
What can be learned from the history of recurrence in migraine? A comment
}

\author{
Peer Tfelt-Hansen
}

Received: 15 June 2009/ Accepted: 21 July 2009/Published online: 25 August 2009

(C) Springer-Verlag 2009

\begin{abstract}
Recurrence was first recognised as a clinical problem in 1989 with the advent of sumatriptan. The history of recurrence in early sumatriptan randomised clinical trials is described. Recurrence has been ascribed to patientdependent factors but experience with ergot alkaloids suggested that recurrence can also be treatment-dependent. Possible mechanisms for recurrence are discussed.
\end{abstract}

Keywords Triptans $\cdot$ Recurrence $\cdot$ Ergotamine

"This may imply that novel sumatriptan-like drugs with a more rapid or extensive absorption or a longer plasma half-life may not result in higher initial response rates or prevention of headache recurrence" [1]

\section{Introduction}

It is noteworthy that recurrence was not perceived as a "specific clinical problem" in migraine therapy before the advent of sumatriptan in the large clinical trial programme which resulted in its introduction into clinical use of the drug [2]. For the migraine patients no recurrence is one of the most important attribute of triptan therapy [3-5]. Attempts to avoid recurrence with triptans, either by using a second dose of sumatriptan or by using triptans with longer elimination half-lives, have largely been

P. Tfelt-Hansen $(\bowtie)$

Danish Headache Centre, Department of Neurology, Glostrup

Hospital, University of Copenhagen, Glostrup, Denmark

e-mail: ptha@glo.regionh.dk unsuccessful. In order to avoid recurrence, its mechanism should be better elucidated.

In the following, the history of recurrence in migraine treatment from 1989 onwards will be recapitulated. In addition, the question of whether recurrence is patientdependent will be examined, and possible mechanism of recurrence will be discussed.

\section{History of recurrence}

Early on in 1989, during the open phase II studies, attention was drawn to the clinical problem of recurrence. Thus, in an open study on subcutaneous sumatriptan 2-3 mg, ten patients in one Danish centre were given a questionnaire concerning recurrence within 24 h of treatment in the clinic by Dr. Iversen, Gentofte Hospital, Denmark [6]. Five out of ten migraine patients experienced that the migraine headache recurred within $24 \mathrm{~h}$ after successful treatment in the first case and these recurrences occurred within the usual duration of the migraine attack [6]. In the other centres, there was no systemic follow-up after the patients left the clinic, and only one recurrence was observed in 101 patients [6]. This clearly demonstrated that in order to observe recurrence one had to look for it by administration of a questionnaire about it.

In the first edition of the guidelines [7] on clinical drug trials in migraine of the International Headache Society from 1991 the proposed primary efficacy parameter was as follows: Number of attacks resolved within $2 \mathrm{~h}$. It was recommended that "number of migraine attacks resolved within $2 \mathrm{~h}$, before any escape medication, should usually be the primary parameter of efficacy. Whenever an attack remits within $2 \mathrm{~h}$, and relapses within $24 \mathrm{~h}$, it is a treatment failure by this criterion" [7]. In practice this parameter is 
roughly similar to the later in 2000 proposed "sustained pain-free" parameter which is defined "as pain-free within $2 \mathrm{~h}$ with no use of escape medication or relapse within $48 \mathrm{~h}$ " [8]. This was later modified to $24 \mathrm{~h}$ in the Lancet meta-analysis [9]. In the comments from 1991 [7] it was noted that "if a drug is effectively quickly in bringing resolution of the attack, but the attack relapses because of a short duration of action of the drug (as has been observed in patients with longlasting attacks), repeated intake of the same drug can be optional; this requires a special study design" [7]. Thus the committee members were aware of the problem of recurrence most likely by personal experiences from the then ongoing extensive sumatriptan trial programme [2].

In the triptan development programmes, recurrence has been defined as headache relief (a decrease in headache from moderate or severe to mild or none) after $2 \mathrm{~h}$ and recurrence of moderate or severe headache within $24 \mathrm{~h}$.

In one of the first randomised clinical trials (RCTs) on subcutaneous sumatriptan $6 \mathrm{mg}$ in 1991 recurrence was not mentioned [10]. It was concluded in this American RCT "that sumatriptan is an effective treatment for patients with migraine. A significant reduction in headaches, clinical disability, nausea, and photophobia occurs within minutes of a subjections injection, with lasting effects for up to $24 \mathrm{~h}$ " [10]. However, the patients kept a diary for $48 \mathrm{~h}$ after receiving treatment and this conclusion was reached despite the fact that only $34 \%$ of the patients remained completely pain free for $24 \mathrm{~h} \mathrm{[10].} \mathrm{Also} \mathrm{in} \mathrm{the} \mathrm{large} \mathrm{oral}$ dose-defining study from 1991 there was no mention of recurrence and no mention of a follow-up after treatment [11].

Even in 1992 it was noted in a paper [12] on CNS adverse events of subcutaneous sumatriptan that these AEs had a short-lasting time profile parallel to the kinetics of the drug whereas" the pharmacodynamic effect with respect to headache, however, last for about 24 h" [10]".

In contrast, a multiple-dose study of oral sumatriptan from 1991 reported recurrence in $48 \%$ of sumatriptantreated patients [13]. Similarly, in an international RCT on subcutaneous sumatriptan, $6 \mathrm{mg}$ which was done at the same time, it was observed that the migraine recurred in $38 \%$ of patients within $24 \mathrm{~h}$ after subcutaneous sumatriptan $6 \mathrm{mg}$ [14] Thus even with the most effective way of administering a triptan a considerable recurrence rate was found $[15,16]$.

In the two comparative RCTs, published in 1991 and 1992, in which oral sumatriptan (recurrence in 41-42\%) was compared with ergotamine (30\%), and aspirin plus metoclopramide (33\%) recurrence was evaluated [17, 18]. From this time on, recurrence was evaluated in almost all RCTs with triptans $[16,19,20]$.
From 2000 when IHS [6] recommended sustained painfree and after the meta-analysis of oral triptans from 2001 in the Lancet [9], most studies have reported on this efficacy measure instead of headache recurrence. In the metaanalysis $[9,21]$ a rather low sustained pain-free response was found. Thus for sumatriptan $100 \mathrm{mg}$ sustained pain free $2-24 \mathrm{~h}$ was $20 \%$ and for rizatriptan $10 \mathrm{mg}(25 \%)$, eletriptan (25\%) and almotriptan (27\%) it was somewhat higher [21]. Even so, with the best oral treatment at that time less than one-third of patients had a sustained painfree response.

Whereas addition of a second dose of sumatriptan did not prevent headache recurrence [22-24] the combination of sumatriptan $85 \mathrm{mg}$ and naproxen $500 \mathrm{mg}$ resulted in more patients $(24 \%)$ being sustained pain-free than after sumatriptan $85 \mathrm{mg}(16 \%)$ [25].

\section{Is recurrence attack- or patient-dependent?}

The pros and cons of recurrence being attack- or patient dependent versus treatment-dependent are summarised in Table 1. First, a second dose of oral sumatriptan $100 \mathrm{mg}$ was tried as a preventive drug for recurrence [22-24]. Sumatriptan was given double-blindly $2-4 \mathrm{~h}$ after an openlabelled first dose of either subcutaneous [22] or oral sumatriptan $[23,24]$. The second dose of sumatriptan did not decrease the incidence of recurrence compared with placebo $[22,23,25]$. This indicated that the incidence of recurrence did not correlate with the pharmacokinetics of sumatriptan. In contrast, sumatriptan was found effective in the treatment of recurrence in four RCTs [16].

In two studies from 1996, Visser et al. [1, 26] investigated the problem of recurrence. In one study in 366 migraine patients risk factors for recurrence were evaluated. Headache recurrence occurred more frequently in patients with more severe attacks and longer untreated attack duration [25] In a second study, Visser et al. [1] could find no correlation between the recurrence of migraine and the pharmacokinetics parameters or the pharmacodynamics parameters (effect on cranial arteries as measured by ultrasound) of subcutaneous sumatriptan studied outside attacks. They concluded that recurrence is most likely patient-dependent [1] and that the results "may imply that novel sumatriptan-like drugs with a more rapid or extensive absorption or a longer plasma half-life may not result in higher initial response rates or prevention of headache recurrence" [1]. Multivariate logistic regression analysis of the eletriptan trial programme identified predictors of headache recurrence [27]. These predictors were age of $>35$ years, females and severe attacks at baseline [27]. This indicates that the recurrence is mainly patientdependent. 
Table 1 Is recurrence attack- or patient-dependent?

\begin{tabular}{|c|c|c|}
\hline References & Methods & Result \\
\hline $\begin{array}{l}\text { Rapoport et al. [22], Ferrari } \\
\text { et al. [23], Scott et al. [24] }\end{array}$ & $\begin{array}{l}\text { Administration of sumatriptan } 100 \mathrm{mg} \text { or placebo as } \\
\text { a second dose after } 2-4 \mathrm{~h} \text { for the prevention of } \\
\text { recurrence }\end{array}$ & $\begin{array}{l}\text { No effect of sumatriptan on the incidence of } \\
\text { recurrence compared with placebo }\end{array}$ \\
\hline Visser et al. [26] & Analysis of 366 migraine patients & $\begin{array}{l}\text { Recurrence more frequently with severe attacks and } \\
\text { long duration of untreated attacks }\end{array}$ \\
\hline Visser et al. [1] & $\begin{array}{l}\text { Pharmacokinetic and pharmacodynamic evaluation } \\
\text { after subcutaneous sumatriptan in migraine } \\
\text { patients outside attacks }\end{array}$ & $\begin{array}{l}\text { No differences between patients with recurrence and } \\
\text { non-recurrence patients }\end{array}$ \\
\hline Dodick et al. [27] & $\begin{array}{l}\text { Multivariate logistic regression analysis identified } \\
\text { predictors of headache recurrence in the eletriptan } \\
\text { trial program }\end{array}$ & $\begin{array}{l}\text { Predictors of recurrence were: }>35 \text { years old, } \\
\text { females, and severe attacks at baseline }\end{array}$ \\
\hline Tfelt-Hansen [32] & $\begin{array}{l}\text { RCT of frovatriptan }\left(t_{1 / 2}=26 \mathrm{~h}\right) \text { versus sumatriptan } \\
\left(t_{1 / 2}=2 \mathrm{~h}\right)\end{array}$ & $\begin{array}{l}\text { Frovatriptan ( } 25 \% \text { recurrence) was not different } \\
\text { from sumatriptan }(31 \% \text { recurrence })^{\mathrm{a}}\end{array}$ \\
\hline $\begin{array}{l}\text { Saxena and Tfelt-Hansen } \\
\text { [16] }\end{array}$ & $\begin{array}{l}\text { Comparative RCTs of a triptan versus ergot } \\
\text { alkaloids }\end{array}$ & $\begin{array}{l}\text { In five out of six RCTs significant less recurrence } \\
\text { with ergot alkaloids than with a triptan }\end{array}$ \\
\hline Brandes et al. [25] & $\begin{array}{l}\text { RCT of naproxen plus sumatriptan versus } \\
\text { sumatriptan }\end{array}$ & $\begin{array}{l}\text { More sustained pain-free ( } 24 \%) \text { after naproxen plus } \\
\text { sumatriptan than after sumatriptan }(15 \%)\end{array}$ \\
\hline
\end{tabular}

${ }^{a}$ See Fig. 1 for a possible explanation

In 2003, Géraud et al. [28] found a correlation between the half-lives and recurrence rates of oral triptans. However, the incidence of recurrence depends on female gender, age of $\geq 35$ years, and severe baseline characteristics [27], as mentioned above, and these factors were not included in the analysis [28] To illustrate, in two RCTs with zolmitriptan the treated migraine headache was moderate in $73-75 \%$ of patients $[29,30]$, whereas in one RCT with rizatriptan the treated migraine headache was severe in $55 \%$ of patients [31]. The recurrence rates in these RCTs with different baseline severity should thus not be compared. Comparison of recurrence rates or sustained pain-free response should thus only be performed in direct comparative RCTs in which randomisation ensures comparable baseline severity of migraine headache and the other predictors for recurrence [27].

In the analysis of recurrence with oral triptans [28] recurrence rates of $17 \%$ for frovatriptan $2.5 \mathrm{mg}$ and $33 \%$ for sumatriptan $100 \mathrm{mg}$ were used. In contrast, in a direct comparative RCT frovatriptan $2.5 \mathrm{mg}$ ( $25 \%$ recurrence) with a half-life of $26 \mathrm{~h}$ did not result in significantly fewer recurrences than sumatriptan $100 \mathrm{mg}$ (31\% recurrence) with a half-life of $2 \mathrm{~h}$ [32]. This indicates that even with a huge difference in elimination $t_{1 / 2}$ among two triptans there is no difference in recurrence. The most likely explanation for this is that low triptan levels, as illustrated in Fig. 1, do not influence the risk for recurrence.

In summary, there are thus several pros for recurrence being attack- or patient-dependent.

In contrast, the effect of ergot alkaloids, less recurrence than a triptan in five out of six RCTs in which this parameter was measured [16] speaks strongly against

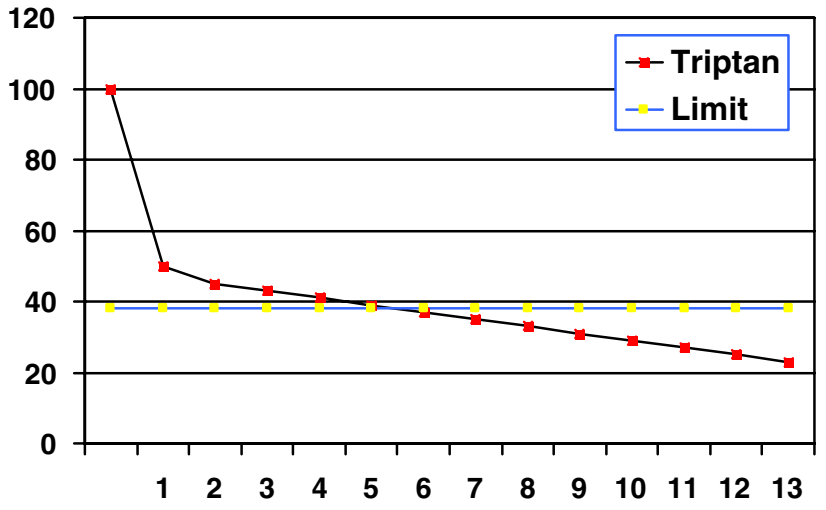

Fig. 1 Plasma concentration of a hypothetical triptan with a terminal elimination half-life of $12 \mathrm{~h}$. The hypothetical limiting concentration for an effect in migraine is shown by the horizontal line. After $6 \mathrm{~h}$ the drug has no longer any anti-migraine effect and can recur

recurrence being patient-dependent. Similarly, the combination of sumatriptan and naproxen [24] resulted in more patients being sustained pain-free (24\%) than after sumatriptan $(16 \%)$ indicating a treatment factor for recurrence.

\section{Possible mechanism of recurrence in migraine}

Some patients have migraine attacks which if untreated last up to $72 \mathrm{~h} \mathrm{[33].} \mathrm{It} \mathrm{is} \mathrm{a} \mathrm{clinical} \mathrm{observation} \mathrm{that} \mathrm{if} \mathrm{they} \mathrm{are}$ treated with a triptan they risk multiple recurrences with intake of triptans one to two times a day for several days. This indicates that the migraine process continues despite symptomatic relief by a drug. It has correspondingly been shown with PET scan that even after successful treatment 
with subcutaneous sumatriptan the brainstem activation found during migraine attacks is persistent $[34,35]$. The brain stem activation has been termed the "migraine generator" [36]. Also the postdromes, the most common being tiredness, observed in $68 \%$ of patients, indicate [37] that a process is ongoing after the actual attack. Similarly, adverse events such as sedation after triptans occur more frequently after successful treatment indicating demasking of symptoms of the migraine attack [38]. One theoretical way to circumvent this problem is the using of triptan with a very long half-life, e.g., frovatriptan with a $t_{1 / 2}$ of $26 \mathrm{~h}$ (Table 1). However, as suggested in Fig. 1 the terminal $t_{1 / 2}$ may theoretically not be relevant for recurrence.

Finally, pharmacodynamics may be more important than pharmacokinetics for recurrence. Ergotamine has a kinetic $t_{1 / 2}$ of $2 \mathrm{~h}$, but a pharmacodynamic $t_{1 / 2}$ of $10 \mathrm{~h} \mathrm{[39]} \mathrm{due} \mathrm{to} \mathrm{a}$ tight binding to the arterial receptor. Thus, in vitro the constrictor effect of ergotamine on human temporal and coronary arteries cannot be washed out [40-42].

In rat middle cerebral artery the contractions induced by ergotamine and dihydroergotamine (DHE) were typically slow in on and off set (about 30-60 min) [43]. The long duration of ergot alkaloids should be investigated further in an attempt to design drugs with less recurrence [43]. DHE has a terminal $t_{1 / 2}$ of $10 \mathrm{~h}$ but, is in my opinion, more likely the tight binding to the receptor that is important [44].

The slow dissociation from the receptor on arteries of DHE and ergotamine also explains the slow onset of action of ergot alkaloids (Fig. 2). The ergot alkaloids' behaviour, slow onset of action, and long duration of action, fits best with an effect on arteries [39] or veins [44, 45].

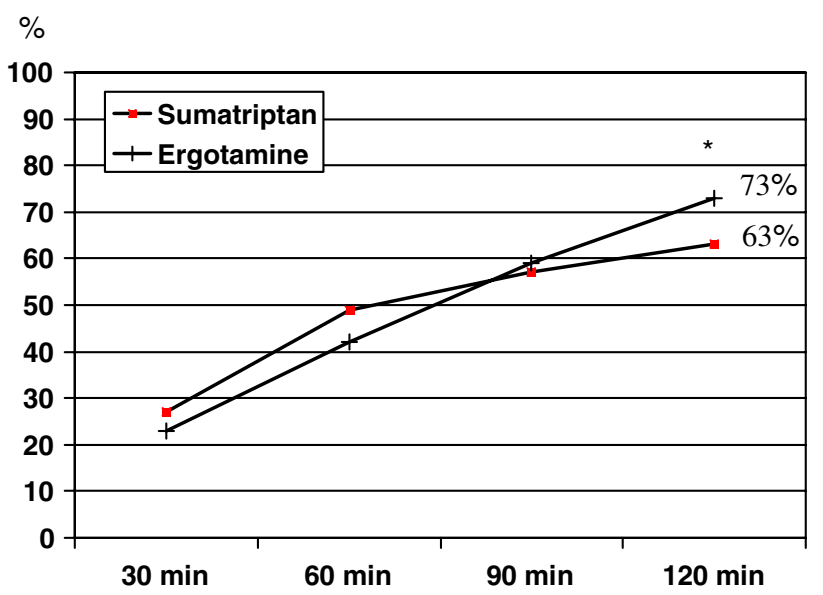

Fig. 2 Comparison of rectal sumatriptan $25 \mathrm{mg}$ with ergotamine tartrate $2+200 \mathrm{mg}$ caffeine in the treatment of migraine attacks. Percentage headache relief (a decrease from moderate or severe headache to none or mild headache) after the two drugs are given. Note that in the first hour sumatriptan was superior to ergotamine whereas after $2 \mathrm{~h}$ ergotamine ( $73 \%$ relief) was superior to sumatriptan $(* P<0.05)[20]$

\section{Conclusion}

Recurrence appeared as a significant clinical problem in the large trial programme of sumatriptan. So far, attempts to avoid recurrence have not been successful. Recurrence is most likely both patient-dependent, viz. severe and long-lasting untreated attacks which increase the risk of recurrence [26], and treatment-dependent, viz. the longer pharmacodynamic effect of ergot alkaloids with resulting less recurrence $[16,39]$. Among the triptans there are only minor, but sometimes statistically significant differences in recurrence and sustained pain-free responses $[8,21]$. The ideal drug for migraine should have a quick onset of action like triptans and a long duration of effect like ergot alkaloids. This could theoretically, however, based on the pharmacodynamic factors mention above, be a futile endeavour.

\section{Conflict of interest None.}

\section{References}

1. Visser WH, Burggraaf J, Muller LM, Schoemaker RC, Fowler PA, Cohen AF, Ferrari MD (1996) Pharmacokinetic and pharmacodynamic profiles of sumatriptan in migraine patients with headache recurrence or no response. Clin Pharmacol Ther 60:452-460

2. Pilgrim AJ (1991) Methodology of clinical trials of sumatriptan in migraine and cluster headache. Eur J Neurol 31:295-299

3. Lipton RB, Hamelsky SW, Dayno JM (2002) What do patients with migraine want from acute migraine treatment? Headache 42(suppl 1):S3-S9

4. Lantéri-Minet M (2005) What do patients want from their acute migraine therapy? Eur Neurol 53(suppl 1):3-9

5. Gallagher R (2004) What do patients want from acute migraine treatment? Cephalalgia 24(suppl 2):8-15

6. Tfelt-Hansen P, Brand J, Dano P, Doenicke A, Findley LJ, Iversen HK et al (1989) Early clinical experience with subcutaneous GR43175 in acute migraine: an overview. Cephalalgia 9(suppl 9):73-77

7. International Headache Society Committee on Clinical Trials in Migraine (1991). Guidelines for controlled trials of drugs in migraine, 1st edn. Cephalalgia 11:1-12

8. International Headache Society Clinical Trial Subcommittee (2000). Guidelines for controlled trials of drugs in migraine, 2nd edn. Cephalalgia 20:765-786

9. Ferrari MD, Roon KI, Lipton RB, Goadsby PJ (2001) Oral triptans (serotonin 5-HT1B/1D agonists) in acute migraine treatment: a meta-analysis of 53 trials. Lancet 358:1668-1675

10. Cady RK, Wendt JK, Kirchner JR, Sargent JD, Rothrock JF, Skaggs H Jr (1991) Treatment of acute migraine with subcutaneous sumatriptan. JAMA 265:2831-2835

11. The Oral Sumatriptan Dose-Defining Study Group (1991) Sumatriptan - an oral dose-defining study. Eur Neurol 31:300-305

12. Sullivan JT, Preston KL, Testa MP, Busch M, Jasinski DR (1992) Psychoactivity and abuse potential of sumatriptan. Clin Pharmacol Ther 52:635-642

13. The Oral Sumatriptan International Multiple-Dose Study Group (1991) Evaluation of a multiple-dose regimen of oral sumatriptan for the acute treatment of migraine. Eur Neurol 31:306-313 
14. The Subcutaneous Sumatriptan International Study Group (1991) Treatment of migraine attacks with sumatriptan. N Eng J Med 325:316-321

15. Tfelt-Hansen P, De Vries P, Saxena PR (2000) Triptans in migraine. A comparative review of pharmacology, pharmacokinetics and efficacy. Drugs 60:1259-1287

16. Saxena PR, Tfelt-Hansen P (2006) Triptans, 5HT1B/1D agonists in the acute treatment of migraine. In: Olesen J, Goadsby PJ, Ramadan NM, Tfelt-Hansen P, Welch KMA (eds) The headaches, 3rd edn. Lippincott Williams \& Wilkins, Philadelphia, pp 469-503

17. The Oral Sumatriptan and Aspirin plus Metoclopramide Comparative Study Group (1992) A study to compare oral sumatriptan with oral aspirin plus oral metoclopramide in the acute treatment of migraine. Eur Neurol 32:177-184

18. Multinational Oral Sumatriptan and Cafergot Coparative Study Group (1991) A randomized, double-blind comparison of sumatriptan in the acute treatment of migraine. Eur Neurol 31:314-322

19. Saxena PR, Tfelt-Hansen P (1993) Sumatriptan. In: Olesen J, Tfelt-Hansen P, Welch KMA (eds) The headaches. Ravens Press, New York, pp 329-341

20. Saxena PR, Tfelt-Hansen P (2000) Triptans, 5-HT $1 \mathrm{~B} / 1 \mathrm{D}$ receptor agonists, in the acute treatment of migraine. In: Olesen J, TfeltHansen P, Welch KMA (eds) The headaches, 2nd edn. Lippincott Williams \& Wilkins, Philadelphia, pp 411-438

21. Ferrari MD, Goadsby PJ, Roon KI, Lipton RB (2002) Triptans (serotonin, 5- $\mathrm{HT}_{1 \mathrm{~B} / 1 \mathrm{D}}$ agonists) in migraine: detailed results and methods of a meta-analysis of 53 trials. Cephalalgia 22:633-658

22. Rapoport A, Visser WH, Cutler NR, Alderton CJ, Paulsgrove LA, Davis RL et al (1995) Oral sumatriptan in preventing headache recurrence after treatment of migraine arracks with subcutaneous sumatriptan. Neurology 45:1505-1509

23. Ferrari MD, James MH, Bates D, Pilgrim A, Ashford E, Andersson BA (1994) Oral sumatriptan: effect of a second dose, and treatment of headache recurrence. Cephalalgia 14:330-338

24. Scott RJ, Aitchison WRC, Barker PR, McLaren GI (1996) Oral treatment in the acute treatment of migraine and migraine and migraine recurrence in general practice. Q J Med 89:613-622

25. Brandes JL, Kudrow D, Stark SR, O'Carroll CP, Adelman JU, O'Donnell FJ et al (2007) Sumatriptan-naproxen for acute treatment of migraine. A randomized trial. JAMA 297:1443-1454

26. Visser WH, Jaspers NM, de Vriend RH, Ferrari MD (1996) Risk factors for headache recurrence after sumatriptan. A study in 366 migraine patients. Cephalalgia 16:264-269

27. Dodick DW, Lipton RB, Goadsby PJ, Tfelt-Hansen P, Ferrari MD, Diener H-C, Almas M, Albert KS, Parsons B (2008) Predictor of migraine headache recurrence a pooled analysis from the eletriptan data base. Headache 48:184-193

28. Géraud G, Keywood C, Senard JM (2003) Migraine headache recurrence: relationship to clinical, pharmacological, and pharmacokinetic properties of triptans. Headache 43:376-388

29. Dodick D, Brandes J, Elkind A, Mathew N, Rodichok L (2005) Speed of onset, efficacy and tolerability of zolmitriptan nasal spray in the acute treatment of migraine: a randomised, doubleblind, placebo-controlled study. CNS Drugs 19:125-136

30. Spierings EL, Rapoport AM, Dodick DW, Charlesworth B (2004) Acute treatment of migraine with zolmitriptan $5 \mathrm{mg}$ orally disintegrating tablet. CNS Drugs 18:1133-1141

31. Tfelt-Hansen P, Teall J, Rodriguez F, Giacovazzo M, Paz J, Malbecq W, Block GA, Reines SA, Visser WH on behalf of the Rizatriptan 030 study Group (1998) Oral rizatriptan versus oral sumatriptan: a direct comparative study in the acute treatment of migraine. Headache 38:748-755

32. Tfelt-Hansen P (2008) Frovatriptan and data publication. Headache 48:1382-1383

33. Headache Classification Committee of the International Headache Society (2004) Classification and diagnostic criteria for headache disorders, cranial neuralgia and facial pain, 2nd edn. Cephalalgia 24(suppl 1):1-164

34. Weiller C, May A, Limmroth V, Jüptner M, Kaube H, Schayck RV et al (1995) Brainstem activation in spontaneous human migraine attacks. Nat Med 1:658-660

35. Afridi SK, Matharu MS, Lee L, Kaube H, Friston KJ, Frackowick RS et al (2005) A PET study exploring the laterality of brainstem activation in migraine using glyceryl trinitrate. Brain 128:932-939

36. Diener HC, May A (1996) New aspects of migraine pathophysiology: lessons learned from positron emission tomography. Curr Opin Neurol 9:199-201

37. Kelman L (2006) The postdrome of the acute migraine attack. Cephalalgia 26:214-220

38. Goadsby PJ, Dodick D, Almas M, Diener H-C, Tfelt-Hansen P, Lipton RB, Parsson B (2007) Treatment emergent CNS symptoms following triptan therapy are part of the migraine attack. Cephalalgia 27:254-262

39. Tfelt-Hansen P, Paalzow L (1985) Intramuscular ergotamine: plasma levels and dynamic activity. Clin Pharmacol Ther 37:29-35

40. Østergaard JR, Mikkelsen E, Voldby B (1981) Effects of 5hydroxytryptamine and ergotamine on human superficial temporal artery. Cephalalgia 1:223-228

41. Tfelt-Hansen P, Østergaard JR, Göthgen I, Jacobsen E, Rasmussen JP, Husum B (1982) Nitroglycerin for ergotism-experimental studies in vitro and in migraine patients and treatment of an overt case. Eur J Clin Pharmacol 22:105-109

42. MaassenVanDenBrink A, Reekers M, Bax WA, Ferrari MD, Saxena PR (1998) Coronary side effect potential of current and prospective antimigraine drugs. Circulation 98:25-30

43. Tfelt-Hansen P, Nilsson E, Edvinsson L (2007) Contractile responses to ergotamine and dihydroergotamine in the perfused middle cerebral artery of rat. J Headache Pain 8:83-89

44. Müller-Schweinitzer E (1984) What is known about the action of dihydroergotamine on the vasculature in man? Int J Clin Pharmacol Ther Toxicol 22:677-682

45. Müller-Schweinitzer E (1980) In vitro study on the duration of action of dihydroergotamine. Int J Clin Pharmacol Ther Toxicol 18:88-91 